\title{
Covid-19 Pandemic and Independent Convenience Stores in the United Kingdom
}

\author{
Maria Rybaczewska ${ }^{1}$, Lukasz Sulkowski ${ }^{2}$, Yuriy Bilan ${ }^{3}$
}

${ }^{1}$ University of Stirling

FK9 4LA Stirling, UK

University of Social Sciences

ul. Sienkiewicza 9, 90-113 Lodz, Poland

E-mail.maria.rybaczewska@stir.ac.uk

${ }^{2}$ Jagiellonian University

ul. Golebia 24, 31-007 Kraków, Poland

E-mail.lukasz.sulkowski@uj.edu.pl

${ }^{3}$ Alexander Dubcek University of Trencin

Studentska 1639/2, 91101 Trencin, Slovakia

Sumy State University

Ryms'koho-Korsakova St, 2, Sumy, 40-000 Ukraine

E-mail.yuriy_bilan@yahoo.co.uk

cross $^{r e f}$ http://dx.doi.org/10.5755/j01.ee.32.3.28360

Covid-19 brought the new reality into every-day life, global economy, and various sectors, including independent convenience stores. After the first and during the second wave of Coronavirus in the United Kingdom (mid-November 2020), the overall situation was very dynamic and turbulent. This paper is thus aimed at answering the question how the independent convenience stores sector in the United Kingdom functions in the Covid-19 reality. We analyse such issues as the recession phase in the global economy, and challenges the independent convenience stores sector in the UK faces, including the changing aspects of the consumer shopping behaviour. We identify the changes in the footfall, basket spend, sale, product categories, etc. Finally, we conclude that the convenience store sector in the UK is relatively resistant to Covid-19 pandemic and emphasise the most challenging consumer behaviour aspects in the middle of the Covid-19 pandemic.

Keywords: Covid-19; Pandemic; Retail; Independent Convenience Stores Sector; the United Kingdom.

\section{Introduction}

The Covid-19 pandemic has brought many unexpected and uncommon regulations and circumstances that societies and economies face. Some consequences are already known (mid-November 2020), some are still impossible to be identified and predicted. The situation is extremely complex and dynamic in all various fields, e.g. health (Brose et al., 2020; Zvolensky et al., 2020), safety (Tahir \& Batool, 2020; Urch \& George, 2020), economics (Bonaparte, 2020; Fetzer et al., 2020), retail (Roggeveen \& Sethuraman, 2020; Vaitkevicius et al., 2019), and consumer behaviour (Kirk and Rifkin, 2020; Sheth, 2020). Uncertainty becomes the most prevalent characteristic of the current reality in all dimensions, from the global economy to every single household and/or individual. The overall trends, including globalisation, are not as certain as before and the 'new normal' is very difficult to define (Leiva-Leon et al., 2020; Sulkowski, 2020). We address the issue of these Covid-19 consequences and new circumstances from the perspective of the convenience stores sector that generates an impressive number of vacancies in the job market and highly influences local communities (Rybaczewska \& Sparks, 2020). The contribution of this paper is thus twofold: firstly, to document and analyse the situation of the independent convenience stores sector in the UK after the first and during the second wave of the Covid-19 pandemic; secondly, to interpret the changes caused by Covid-19. We focus on specific aspects of consumer shopping behaviour in independent convenience stores under the unprecedented circumstances of lockdown and pandemic. Consequently, our study is aimed at widening the discussion on the current reality (mid-November 2020) and possible scenarios for the future of the independent convenience stores sector facing the challenging short- and long-term implications of the Covid-19 pandemic.

The paper comprises six main sections. The introduction is followed by the conceptual framework. It addresses the following: firstly, the complex Covid-19 reality and consequences from the perspective of the global economy (2.1); secondly, the meaning of the independent convenience stores sector in the UK (2.2); thirdly, the knowledge gap in the current situation of the independent convenience stores sector in the UK under the Covid-19 pandemic (2.3). The fourth section of the paperdiscusses the research findings, preceded by the methodology that explains the applied research procedure. Conclusions and Implications comes as the fifth section of the paper and is 
followed by Limitations and Future Research showing our awareness of the issues and remaining tasks where new efforts need to be made.

\section{COVID-19 Pandemic and Independent Convenience Stores: Conceptual Framework}

Covid-19 Pandemic: Global Economy, Social and Cultural Changes

The Covid-19 pandemic has brought significant changes: worldwide recession, deglobalization, and societies/economies going increasingly online (e.g. Bui et al., 2020; Gallant et al., 2020, Sulkowski, 2020).

This self-evident statement results from the observations of the 'second wave' of the pandemic in many countries around the world, where schools are closed down again. Social distancing measures are being reinforced by governments, and global stock exchange indexes are noting rapid drops (Ramelli \& Wagner, 2020). The conomies of many countries plunged into recession in the second quarter of 2020, which was followed by a rebound in the third quarter and a further recession (the fourth quarter of 2020). Considering the extent of the Covid-19 pandemic, its effects are bound to be momentous (Carlsson-Szlezak et al., 2020; Fernandes, 2020; Leiva-Leon et al., 2020)., Showing a few ways the epidemic-effected US economy can possibly develop, Bonaparte (2020) is in favour of taking the most radical actions. There are scholars suggesting that the consequences of the pandemic will cause a crisis in the supply chains and demand, and will eventually lead to the decline in productivity and employment (Fornaro \& Wolf, 2020). Considering the existing inequality in income distribution even in the most developed countries before the pandemic situation (Mishchuk et al., 2018), recent sudden stops in economic activity and sectoral changes in employment can lead to further negative consequences. Interest rates have dropped below zero, and central banks can by no means react effectively (Nicola et al., 2020). Both economic activity and employment are noting sharp declines. As a result, businesses make budget cuts, which leads to the decrease in productivity, that may consequently be followed by further recession (Fornaro \& Wolf, 2020). First of all, these effects will be manifested in labour markets, deepening inconsistencies in labour demand and supply (Bilan et al., 2020). As evidenced by the literature and financial institutions, all of these factors, along with the quarantine and lockdown regime introduced by individual countries, make their economies enter the recession (Gupta et al., 2020). Even though the development of the Covid-19 is likely to impact different areas of the economy to varying degrees, a wide and cross-sectoral decline will be a recognizable phenomenon (Guerrieri et al., 2020). The real impact on economic efficiency and social safety can be more evident within changes in social security systems, particularly, social safety nets activity, due to their influence on quality of life of the population. This impact will be espesially significant for those parts of the population, whose income is generated from the redistribution of tax revenues (Mishchuk et al., 2020). The most sensitive and therefore most gravely affected sectors of the economy relate to culture and leisure time (gastronomy, hotel and tourism, culture and show business, moviemaking industry), health, education, and transport (Albulescu, 2020a). Other business areas, which are most likely to be seriously affected by the pandemic, include financial services (trade, banking, insurance) and fuel extraction and processing (Albulescu, 2020b; Parisi, 2020). For financial markets represented by the foreign exchange sector, fluctuation risks is a ubiquitous feature (Helisek, 2019). In immature markets with high share of mutual funds, financial risks, however, grew unexpectedly, causing essential shifts in activity (Nicolescu et al., 2020). Regional differences in the pandemic consequences reflect the distribution of enterprises and labour force involved in the specific activity (Kuzmenko et al., 2020), including the fields strongly influenced by the pandemic crisis (Cepel et al., 2020; Vo, 2020). This list is by no means complete. Very few areas can count on keeping or increasing their growth rate, and these include the production of pharmaceuticals and medical infrastructure, OHS, and some ICT activities. SMEs without the necessary resources to outlive the crisis will be most threatened by the spread of the pandemic. The interventions of national governments and international financial bodies are likely to belong to the consequences of the growing global economy crisis.

Another effect of the pandemic can be seen in the increasing deglobalisation trends (Balsa-Barreiro et al., 2020; Bollard, 2020; Kozlov \& Sokolova, 2020). To date (midNovember 2020), national governments pioneer decisions regarding the fight against the pandemic. They decide on such matters as the introduction of national emergency states, epidemic risk zones/levels/degrees, closing national borders, banning international flights, putting citizens on quarantine and isolating them if necessary, construction of hospitals (including field hospitals), mobilisation of the military and health services or allocating more financial resources to medical staff. Other institutions such as WHO, EU, or churches play a complementary role to national governments, helping them get stronger after the pandemic. From this point of view, the UK, experiencing the Brexit process and fighting the pandemic at the same time, is a laboratory for deglobalisation solutions in the retail sector.

The spread of the coronavirus has caused a rapid change in the way people communicate in such areas as business, education, local, central, and even global administration, which has noticeably moved online due to the reasons related to health security. This involves not only the growing use of technical infrastructure and software but also means the formation of new social and cultural behaviour. The rapid move to online communication methods will apparently include such activities as controlling, motivating, and training the workforce.

\section{Independent Convenience Stores Sector in the UK}

The importance of the convenience store sector in the UK has been widely acknowledged and confirmed by various credible statistics over the years. The Local Shop Report 2020 prepared by the Association of Convenience Stores shows that there are 46,955 convenience stores in mainland UK. This sector currently employs around 412,000 people, generating sales of over $£ 44.7$ bn over the last year (Association of Convenience Stores, 2020). 
At a time of retail restructuring and changing consumer demands, the convenience sector has been one of the few 'bright spots' in UK retailing (Hood et al., 2016). The expansion of convenience stores has been attributed to meeting changing customer preferences, the enhanced variety of services and products offered and their locational alignment with work, travel and residence. That is why it became an important feature of retail (Rybaczewska and Sparks, 2020).

\section{Independent Convenience Stores Sector in the UK and Covid-19}

Convenience stores are a format that can be operated by various organisational forms. Corporate convenience stores have expanded in the UK (Tesco Metro, Express etc.), but so too have affiliated and symbol groups (e.g. Spar, Premier). Independent and unaffiliated convenience stores are a part of all convenience stores sector $(17.7 \%$ according to the Association of Convenience Stores, Local Shop Report 2020) as the majority tends to affiliate to symbol groups to obtain benefits of sale, marketing, supply chains etc. In most cases they remain, though locally-owned in day to day operation. We concentrate on such stores since it has been suggested that locally-owned convenience stores play a stronger role in both local economy and local society than previously and tend to have stronger and more extensive links than, for example, corporate stores (Rybaczewska \& Sparks, 2020). Taking this into consideration, we emphasise the importance of the independent convenience stores sector in the turbulent Covid-19 pandemic circumstances. If the independent convenience stores play the role of a 'glue for the community' (Sparks, 2019) how their meaning increases in the context of the loneliness and mental problems arising as a kind of lockdown and self-isolation (Miller, 2020; Palgi et al., 2020) widely implemented around the globe in the Covid-19 reality? At the same time when the society and many households and individuals experience the uncertainty to the highest level, how important are the locally-owned, independent convenience stores offering stable jobs (80\% more than one year, including $19 \%$ of more than 10 years employment according to the Association of Convenience Stores, Local Shop Report 2020)? What is this sector's role in assuring the local societies that all their groceries and other everyday product demands can be fully covered in all circumstances (including the Covid-19 pandemic which disrupts transport and supply chains)?

Therefore we address the gap in knowledge regarding the current situation of this meaningful (not only for local economy and society) sector of independent convenience stores in the UK by formulating and answering the below research question:

RQ: How does the independent convenience stores sector in the United Kingdom function in the Covid-19 reality?

\section{Methodology}

Being aware of the advantages and disadvantages of both qualitative and quantitative approach to answer the formulated research question (Bryman \& Bell, 2015; Neuman, 2013; Woodside, 2016), we decided to implement the quantitative methods. It is also connected with the fact that we are interested in up-to-date data and value here the overall objective picture more than in-depth, detailed and subjective opinions.

This research was conducted on a unique dataset created by The Retail Data Partnership Ltd. TRDP has worked with retailers for more than twenty years to help them improve their businesses by developing ShopMate - the convenience sector's most dependable EPoS system. Thanks to the contribution of TRDP we analyse the real-life (not declarative), transactional data drawn from 2,921 independent symbol and unaffiliated convenience stores located in the United Kingdom. All regions were taken into consideration, and specific numbers are as follows: 343 stores in Wales, 259 stores in Scotland, 21 stores in Northern Ireland, 2,298 stores in England. TRDP dataset is highly credible and consistent over time.

The investigated period includes January - September 2019 and January - September 2020. In most cases we concentrate on year-to-year comparisons. Sometimes we underline the overall trend in 2020 or make the long-term observations, starting from previous year(s), depending on the context.

\section{Findings and Discussion}

We identified several determinants enabling the diagnosis of the situation of the independent convenience stores sector in the UK facing the whole variety of symptoms announcing the second wave of Covid-19 pandemic. Among these determinants we put the average store footfall, basket spend, average monthly store gross sales, average store unit sales, products category etc., all contextualised within 2019 data to provide the year to year comparison.

Analysing monthly average footfall between January August 2019 and January - August 2020 (Figure 1), year-toyear comparison shows that, not unexpectedly, the most significant decrease in footfall took place in April 2020. The lockdown was then fully introduced and implemented in the UK (announced on the $12^{\text {th }}$ March 2020, it was not as impactful immediately in March as it was the following month i.e. April 2020). The most current records from July and August 2020 confirm the overall trend of lower footfall in 2020 than in 2019. Interestingly the points in time when the difference was the lowest were January and February 2020 when the Covid-19 pandemic was acknowledged but not that spread yet and the restrictions in the UK were not that strict. 


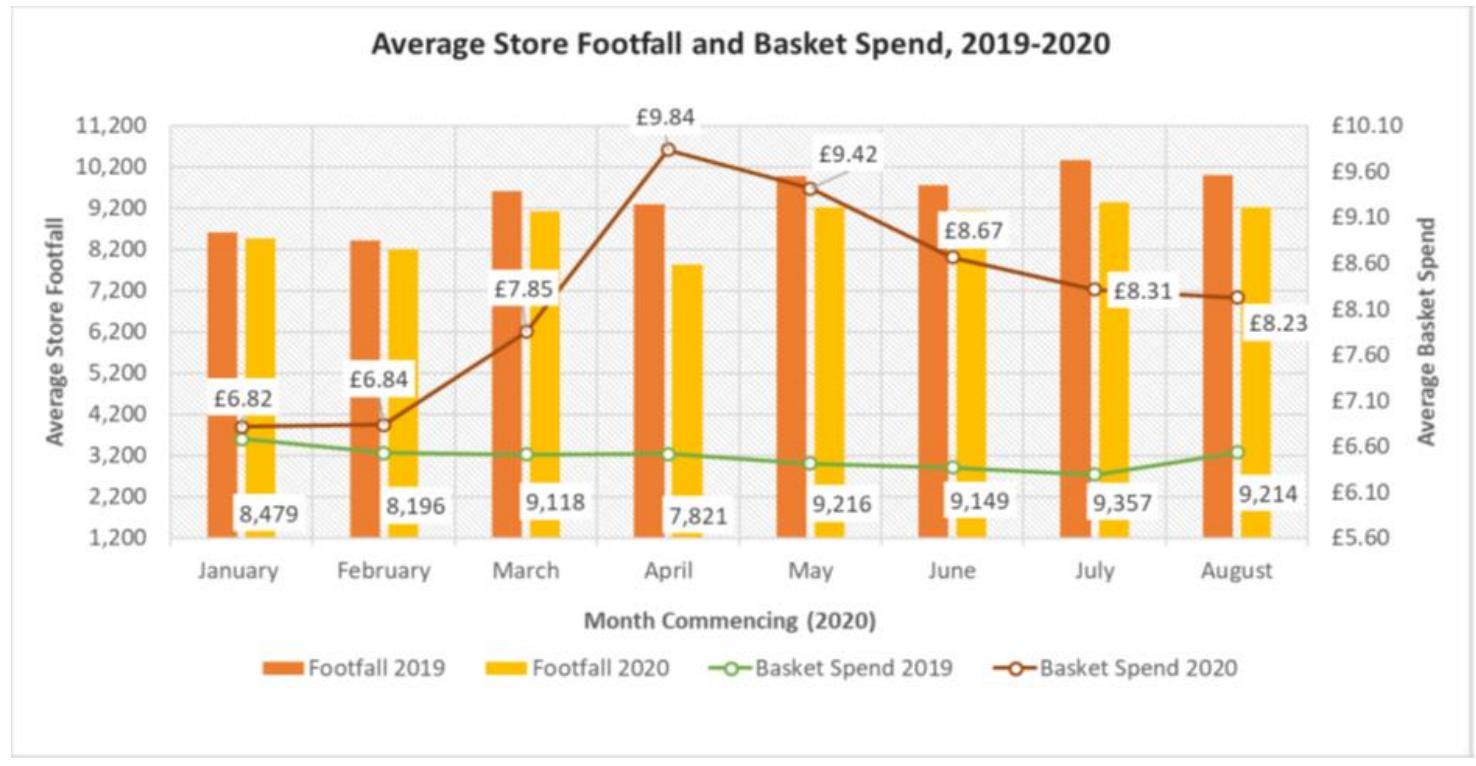

Figure 1. Monthly average footfall, Basket Spend and Sales (January - August 2019 and January - August 2020). Source: The Retail Data Partnership Ltd.

These observations are supported by the survey data concerning the whole convenience stores sector presented in the Local Shop Report 2020 (Association of Convenience Stores, 2020), stating that $40 \%$ of respondents reported decrease in 2020 footfall to a large extent and a small extent $17 \%$ of respondents (in comparison with 2019). At the same time $14 \%$ of respondents admitted that 2020 footfall increased to a large extent and a small extent $23 \%$, all in comparison with 2019.

Another observation refers to the basket spend in the analysed period of time (Figure 1), which shows the totally different situation in 2019 and 2020. There was a huge dynamics in 2020 and rather stable situation in 2019. All records in 2019 were around $£ 6.6$, whereas 2020 differed between $£ 6.8$ and $£ 9.8$. The decreasing footfall was explicitly combined with the increasing basket spend (especially in April). Since April 2020, when the peak was reached, the overall basket spend was decreasing but still was at a far higher level than in 2019.

Contextualising these observations within the situation of the whole convenience stores sector (Association of Convenience Stores, 2020) supports this sector's consistency, irrespectively of the kind of the investigated stores. The reason for that is the fact that almost $50 \%$ of respondents claimed that average basket spend in 2020 increased to a large extent and $29 \%$ reported increase to a small extent. At the same time, only $23 \%$ stated that there was a decrease in the average basket spend (to a large extent $17 \%$, a small extent $6 \%$ ).

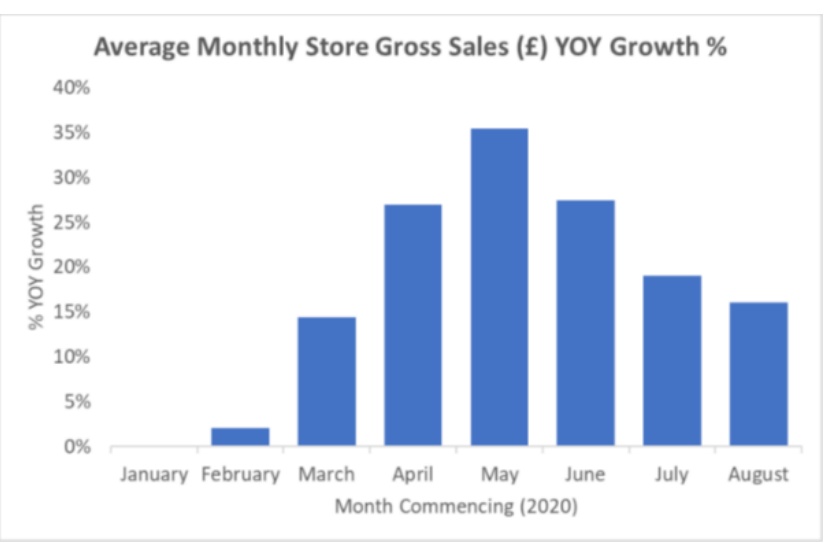

Figure 2. Average Monthly Store Gross Sales (year to year \% growth).

Source: The Retail Data Partnership Ltd.

Another set of variables characterising the current situation of the independent convenience stores sector is the average monthly store gross sales. If the year-to-year growth between January - August 2020 would be taken into consideration (Figure 2) the peak point would not be April 2020 but May 2020. Interestingly there was no growth recorded in January 2020, but it gradually increased since February 2020 and regularly decreased since June 2020. 


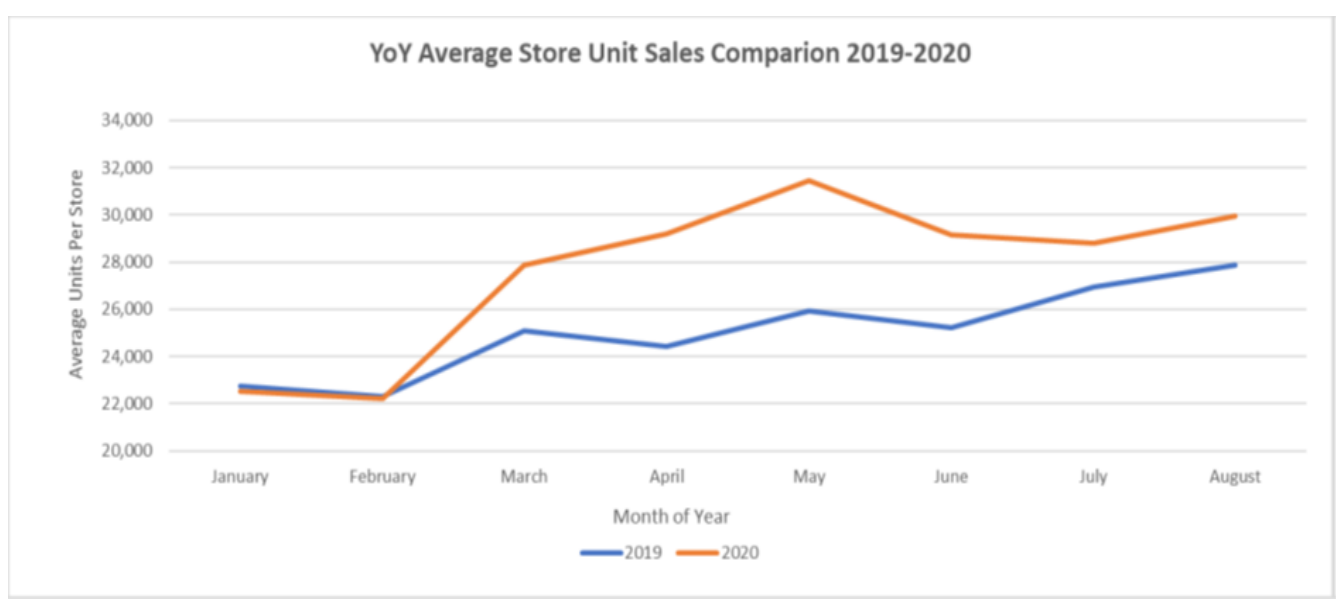

Figure 3. Average Store Unit Sales (year to year comparison 2019 - 2020).

Source: The Retail Data Partnership Ltd.

All these correspond with the average store unit sales comparison (Figure 3), which shows that in January 2020 the average number of units sold per store was almost the same as in 2019. Since then though, it started growing (again the peak in May 2020) and became far closer to 2019 in July and August (but still not at the same level).

The peak point can also be contextualised within the very uncommon situation in many countries, including the UK, connected with the lockdown and transport difficulties. Many consumers, for the very first time in their life, have seen the empty shelves in supermarkets and other stores. How has it changed their shopping behaviour/spend? How did it influence their shopping behaviour at that time? The literature introduces the first voices discussing these questions (Kirk \& Rifkin, 2020; Sheth, 2020) and we would like to join and expand this discussion with our findings. Among others, we can see that March 2020 was the time when canned food was far more frequently shopped than in any other recent times (Figure 4).

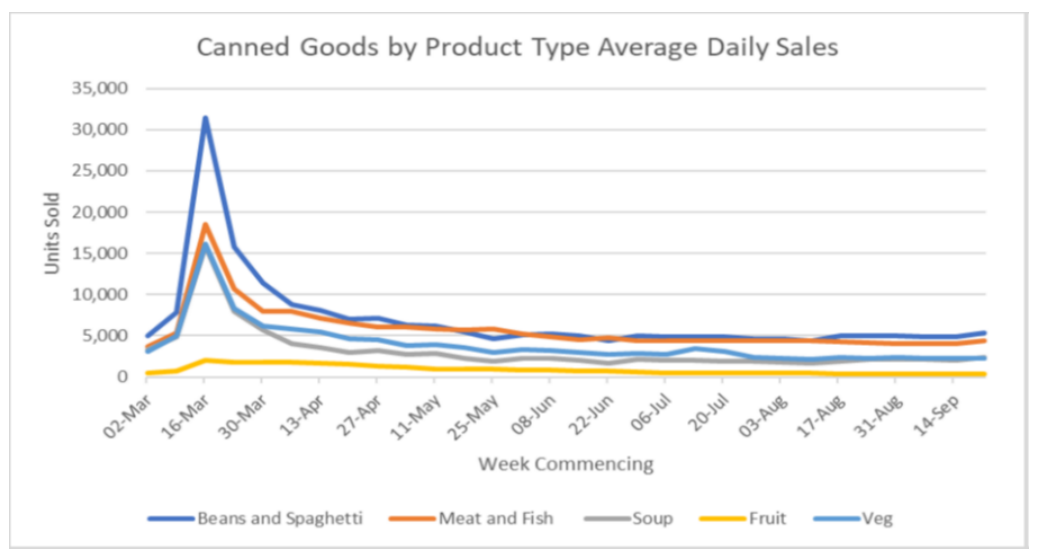

Figure 4. Average Daily Sales of Canned Goods (by product type)

\section{Source: The Retail Data Partnership Ltd.}

Sales value of the whole convenience stores sector (Association of Convenience Stores, 2020) supports these observations since $66 \%$ of respondents noted an increase in this context (to a large extent $38 \%$ and a small extent $28 \%$ ). Simultaneously only $34 \%$ of respondents reported a decrease in the sales value (to a large extent $26 \%$ and a small extent $8 \%$ ).

Another observation refers to product categories most frequently sold in 2019 and 2020 (Association of Convenience Stores, 2020). It shows that the first and second most popular category stayed unchanged (i.e. tobacco and e-cigarettes and alcohol). What's more, in the independent convenience stores, these categories are even more frequently bought in 2020 (32.7 \% tobacco and ecigarettes, $20.1 \%$ alcohol) than they were in 2019 in the whole convenience stores sector $(20.9 \%$ tobacco and ecigarettes, $15.1 \%$ alcohol). The third and fourth most frequently bought categories changed as in 2019 it was chilled foods $(12.8 \%)$ followed by soft drinks $(7.1 \%)$, and in 2020 these included soft drinks (third biggest shares $10.0 \%$ ) and confectionary (on the fourth position $6.6 \%$ ).

\section{Conclusions and Implications}

The footfall analysis showed that year-over-year comparison confirms the impact of the Covid-19 regulations, (including lockdown) on the functioning of the retail in general, and the independent convenience stores sector specifically. Our observations prove the fact that whatever the policymakers decide, every introduced 
solution/regulation comes with wide repercussions for a variety of organisations, business activities, and individuals. The footfall analysis also supports the understanding of the independent convenience stores sector as a part of the entire convenience stores sector being not that different from other kinds of convenience stores (e.g. multiples, symbols) and often characterised by the trends that correspond to the rest of this sector. This is also confirmed by our further findings.

The impact of the Covid-19 pandemic itself and all the related regulations, is meaningful in the context of both consumer behaviour and the independent convenience stores sector. Nevertheless, the implications of this impact can be identified only partially at this stage (mid- November 2020) as the long-term changes are still in progress and can only be forecasted, not specified. Nevertheless, the overall impression of the existence of the trends caused by the Covid-19 pandemic has been confirmed by our and other research findings (Kirk \& Rifkin, 2020; Roggeveen \& Sethuraman, 2020; Sheth, 2020). Therefore, we join the discussion concerning the Covid-19 implications for the overall retail and high streets and town centres addressed by many institutes (e.g. Institute of Place Management, 2020), reports (e.g. PWC, 2020), blogs (e.g. Sparks, 2020), etc. They all confirm the turbulent circumstances that are being faced by all stakeholders in various sectors and emphasise the importance of openness for change and flexibility in current conditions.

Additionally, our analysis underlines the relatively stable and strong position of the convenience stores sector (including independent convenience stores) among other retail sectors. We provide reasons to claim that the convenience stores sector is resistant to the influence of Covid-19 pandemic, which proves its undisputed role in the everyday functioning of local communities and individual households, irrespective of the circumstances.

\section{Limitations and Future Research}

We acknowledge that we did not have access to the discussed issue at the preparation and conducting stages. Therefore, we see that some points are worth further investigationand deeper analysis. We would also desire a more complex approach to particular stages of consumer/buyer decision making process (Rybaczewska et al., 2020; Rybaczewska, Sparks and Sulkowski, 2020) and more sophisticated data on this matter. Nevertheless, we used the accessible data to get a view, as holistic and up-todate as possible, on the independent convenience stores sector after the first and during the second wave of the Covid-19 pandemic in the United Kingdom.

Additionally, our study only provides the quantitative data, which are not as in-depth and comprehensive as the qualitative investigation would be. In the context of such a complex and interdisciplinary issue as the Covid-19 pandemic, the qualitative approach would be a perfect follow-up study, expanding our observations with subjective and psychological dimensions. Nevertheless, this remains a task for the future.

\section{Acknowledgements}

We would like to thank The Retail Data Partnership Ltd. for their willingness to help and contribute to this paper by providing us with the access to incredibly valuable data to the extent that was very helpful.

\section{References}

Albulescu, C. (2020a). Coronavirus and financial volatility: 40 days of fasting and fear. arXiv preprint arXiv:2003.04005. https://doi.org/10.2139/ssrn.3550630

Albulescu, C. (2020b). Coronavirus and oil price crash. Available at SSRN 3553452. https://doi.org/10.2139/ssrn.3553452

Association of Convenience Stores (2020). The Local Shop Report 2020, Available at https://www.acs.org.uk/research/ local-shop-report

Balsa-Barreiro, J., Vie, A., Morales, A. J., \& Cebrian, M. (2020). Deglobalization in a hyper-connected world. Palgrave Communications, 6(1), 1-4. https://doi.org/10.1057/s41599-020-0403-X

Bilan, Y., Mishchuk, H., Roshchyk, I., \& Joshi, O. (2020). Hiring and retaining skilled employees in SMEs: problems in human resource practices and links with organizational success. Business: Theory and Practice, 21(2), $780-791$. https://doi.org/10.3846/btp.2020.12750

Bollard, A. (2020). Globalisation in the Time of Coronavirus. Policy Quarterly, 16(3). https://doi.org/10.2668 6/pq.v16i3.6549

Bonaparte, Y. (2020). Pricing the Economic Risk of Coronavirus: A Delay in Consumption or a Recession? Available at SSRN 3549597.

Brose, A., Blanke, E. S., Schmiedek, F., Kramer, A. C., Schmidt, A., \& Neubauer, A. B. (2020). Change in mental health symptoms during the COVID-19 pandemic: The role of appraisals and daily life experiences. Journal of Personality, 15. https://doi.org/10.1111/jopy.12592

Bryman, A., \& Bell, E. (2015). Business research methods: Oxford University Press, USA.

Bui, T. T. M., Button, P., \& Picciotti, E. G. (2020). Early Evidence on the Impact of Coronavirus Disease 2019 (COVID-19) and the Recession on Older Workers. Public Policy and Aging Report, 30(4), 154-159. https://doi.org/10.1 093/ppar/praa029

Carlsson-Szlezak, P., Reeves, M., \& Swartz, P. (2020). What coronavirus could mean for the global economy. Harvard Business Review, 3. 
Cepel, M., Gavurova, B., Dvorsky, J., \& Belas, J. (2020). The impact of the COVID-19 crisis on the perception of business risk in the SME segment. Journal of International Studies, 13(3), 248-263. https://doi.org/10.14254/2071$8330.2020 / 13-3 / 16$

Fernandes, N. (2020). Economic effects of coronavirus outbreak (COVID-19) on the world economy. Available at SSRN 3557504. https://doi.org/10.2139/ssrn.3557504

Fetzer, T., Hensel, L., Hermle, J., \& Roth, C. (2020). Coronavirus perceptions and economic anxiety. Review of Economics and Statistics, 1-36. https://doi.org/10.1162/rest_a_00946

Fornaro, L., \& Wolf, M. (2020). Covid-19 Coronavirus and Macroeconomic Policy: Some Analytical Notes. http://www.crei.cat/wp-content/uploads/2016/07/CMP.pdf

Gallant, J., Kroft, K., Lange, F., \& Notowidigdo, M. J. (2020). Temporary Unemployment and Labor Market Dynamics During the COVID-19 Recession (No. w27924). National Bureau of Economic Research. https://doi.org/10.33 $86 /$ w27924

Guerrieri, V., Lorenzoni, G., Straub, L., \& Werning, I. (2020). Macroeconomic Implications of COVID-19: Can Negative Supply Shocks Cause Demand Shortages? (No. w26918). National Bureau of Economic Research. https://doi.org/10.3386/w26918

Gupta, M., Abdelmaksoud, A., Jafferany, M., Lotti, T., Sadoughifar, R., \& Goldust, M. (2020). COVID-19 and economy. Dermatologic therapy. https://doi.org/10.1111/dth.13329

Helisek, M. (2019). Exchange Rate Mechanism II and the risk of currency crisis - empiricism and theory. Journal of international studies, 12(1), 297-312. https://doi.org/10.14254/2071-8330.2019/12-1/20

Hood, N., Clarke, G., \& Clarke, M. (2016). Segmenting the growing UK convenience store market for retail location planning. International Review of Retail Distribution and Consumer Research, 26(2), $113-136$. https://doi.org/10.1080/09593969.2015.1086403

Institute of Place Management. (2020). UK High Street Footfall - Daily Index, Available at https://v2.placemanagement. org/uk-footfall-daily-index/

Kirk, C. P., \& Rifkin, L. S. (2020). I'll trade you diamonds for toilet paper: Consumer reacting, coping and adapting behaviors in the COVID-19 pandemic. Journal of Business Research, 117, 124-131. https://doi.org/10.1016/j.jbusres. 2020.05.028

Kozlov, N., \& Sokolova, N. (2020). Deglobalization: The Impact of the External Environment on Russian Economic Development. Norwegian Journal of Development of the International Science, (38-2).

Kuzmenko, O., Vasylieva, T., Vojtovic, S., Chygryn, O., \& Snieska, V. (2020). Why do regions differ in vulnerability to COVID-19? Spatial nonlinear modelling of social and economic patterns. Economics and Sociology, 13(4), 318-340. https://doi.org/10.14254/2071-789X.2020/13-4/20

Leiva-Leon, D., Perez-Quiros, G., \& Rots, E. (2020), Real-time weakness of the global economy: a first assessment of the coronavirus crisis, Banco de Espana Working Papers No. 2015, https://papers.ssrn.com/sol3/papers.cfm? abstract_id=3617695.

Miller, E. D. (2020). Loneliness in the Era of COVID-19. Frontiers in Psychology, 11, 3. https://doi.org/10.33 89/fpsyg.2020.02219

Mishchuk, H., Bilan, S., Yurchyk, H., Akimova, L., \& Navickas, M. (2020). Impact of the shadow economy on social safety: The experience of Ukraine. Economics and Sociology, 13(2), 284-298. https://doi.org/10.14254/2071-789X.2020/13-2/19

Mishchuk, H., Samoliuk, N., Bilan, Y., \& Streimikiene, D. (2018). Income inequality and its consequences within the framework of social justice. Problemy Ekorozwoju, 13(2), 131-138. https://doi.org/10.14254/2071-789X.2020/13-4/20

Neuman, W. L. (2013). Social research methods: Qualitative and quantitative approaches: Pearson education.

Nicola, M., Alsafi, Z., Sohrabi, C., Kerwan, A., Al-Jabir, A., Iosifidis, C., \& Agha, R. (2020). The socio-economic implications of the coronavirus pandemic (COVID-19): A review. International Journal of Surgery (London, England), 78, 185. https://doi.org/10.1016/j.ijsu.2020.04.018

Nicolescu, L., Tudorache, F. G., \& Androniceanu, A. (2020). Performance risk analysis on mutual funds versus stock exchanges in young financial markets. Journal of International Studies, 13(1), 279-294. https://doi.org/10.14254/20718330.2020/13- $1 / 18$

Palgi, Y., Shrira, A., Ring, L., Bodner, E., Avidor, S., Bergman, Y., \& Hoffman, Y. (2020). The loneliness pandemic: Loneliness and other concomitants of depression, anxiety and their comorbidity during the COVID-19 outbreak. Journal of Affective Disorders, 275, 109-111. https://doi.org/10.1016/j.jad.2020.06.036

Parisi, F. (2020). But This Time IS Different-COVID Recession. The Journal of Structured Finance, 26(3), 63-70. https://doi.org/10.3905/jsf.2020.1.113

PWC. (2020). Store closures: twice the rate of last year as net decline now at highest level in five years, Available at https://www.pwc.co.uk/press-room/press-releases/store-closures-twice-the-rate-of-last-year.html

Ramelli, S., \& Wagner, A. F. (2020). Feverish Stock Price Reactions to the Novel Coronavirus. Available at SSRN 3550274 , https://papers.ssrn.com/sol3/papers. cfm?abstract_id=3550274. 
Roggeveen, A. L., \& Sethuraman, R. (2020). How the COVID-19 Pandemic May Change the World of Retailing. Journal of Retailing, 96(2), 169-171. https://doi.org/10.1016/j.jretai.2020.04.002

Rybaczewska, M., \& Sparks, L. (2020). Locally-owned convenience stores and the local economy. Journal of Retailing and Consumer Services, 52, 101939. https://doi.org/10.1016/j.jretconser.2019.101939

Rybaczewska, M., Jirapathomsakul, S., Liu, Y., Chow, W. T., Nguyen, M. T., \& Sparks, L. (2020). Slogans, brands and purchase behaviour of students. Young Consumers. https://doi.org/10.1108/YC-07-2019-1020

Rybaczewska, M., Sparks, L., \& Sulkowski, L. (2020). Consumers' purchase decisions and employer image. Journal of Retailing and Consumer Services, 55, 102123. https://doi.org/10.1016/j.jretconser.2020.102123

Sheth, J. (2020). Impact of Covid-19 on consumer behavior: Will the old habits return or die? Journal of Business Research, 117, 280-283. https://doi.org/10.1016/j.jbusres.2020.05.059

Sparks, L. (2019). The Multiplier and the Glue: Locally owned convenience stores and the local economy, Available at https://stirlingretail.com/2019/09/23/the-multiplier-and-the-glue-locally-owned-convenience-stores-and-the-localeconomy/

Sparks, L. (2020). Openings and Closures in 2020 - but of what?, Available at https://stirlingretail.com/2020/10/21/openings -and-closures-in-2020-but-of-what/

Sulkowski, L. (2020). Covid-19 pandemic; recession, virtual revolution leading to de-globalization? Journal of Intercultural Management, 12(1), 1-11. https://doi.org/10.2478/joim-2020-0029

Tahir, M. B., \& Batool, A. (2020). COVID-19: Healthy environmental impact for public safety and menaces oil market. Science of the Total Environment, 740, 4. https://doi.org/10.1016/j.scitotenv.2020.140054

Urch, C. E., \& George, A. J. T. (2020). Covid-19: Less Haste, More Safety Let's stop talking about covid-safe and covidsecure-it's covid-mitigated. Bmj-British Medical Journal, 370, 1. https://doi.org/10.1136/bmj.m3616

Vaitkevicius, S., Mazeikiene, E., Bilan, S., Navickas, V., \& Savaneviciene, A. (2019). Economic demand formation motives in online-shopping. Inzinerine Ekonomika-Engineering Economisc, 631-640. https://doi.org/10.5755/j01.ee.30. 5.23755

Vo, H. D. (2020). Sustainable agriculture \& energy in the U.S.: A link between ethanol production and the acreage for corn. Economics and Sociology, 13(3), 259-268. https://doi.org/10.14254/2071-789X.2020/13-3/16

Woodside, A. G. (2016). The good practices manifesto: Overcoming bad practices pervasive in current research in business. Journal of Business Research, 69(2), 365-381. https://doi.org/10.1016/j.jbusres.2015.09.008

Zvolensky, M. J., Garey, L., Rogers, A. H., Schmidt, N. B., Vujanovic, A. A., Storch, E. A., \& O'Cleirigh, C. (2020). Psychological, addictive, and health behavior implications of the COVID-19 pandemic. Behaviour Research and Therapy, 134, 16. https://doi.org/10.1016/j.brat.2020.103715

\section{Authors' biographies}

Dr Maria Rybaczewska: academic and business consultant. Cooperating mainly with SMEs, specialising in marketing and retail. Graduated from the International College of Journalism, University of Stirling and Lodz University of Technology. PhD dissertation focused on employer image and purchase decision process of the final buyer was honourably awarded by the Organisation and Management Department of Lodz University of Technology in 2014. Currently employed as a Research Fellow at University of Stirling and cooperating with Clark University Massachusetts and University of Social Sciences in Lodz as an Assistant Professor.

Prof. Lukasz Sulkowski: Full professor of economic sciences and holds a PhD in Humanities. His research interests include organisation and management, and in particular: critical management studies, epistemology and methodology of social sciences and the humanities, organisational culture and intercultural management, public management and management of family businesses. Currently a professor at the Faculty of Management and Social Communication of the Jagiellonian University, at Clark University and the Chair of the Management Department at the University of Social Sciences in Lódź, Poland. A member of the Presidium of the Polish Accreditation Committee since 2012. Since 2008 - the Editor-in-chief of the quarterly 'Journal of Intercultural Management', in 2004-2011 the editor-in-chief of the quarterly 'Organization and Management'.

Assoc. Prof. Yuriy Bilan. He is the President of Centre of Sociological Research (Poland). Since 2008 - the Editor-inchief of the quarterly "Journal of International Studies", Deputy Editor-in-chief of the quarterly "Economics and Sociology". He was fellower 6 th and 7th FP of EU, Human Resources and Mobility Activity, Marii Curie Action. The areas of scientific interest include, but no limit to labour market economy, migration studies and entrepreneurship, sustainable development.

The article has been reviewed.

Received in January 2021; accepted in June 2021.

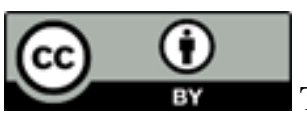

This article is an Open Access article distributed under the terms and conditions of the Creative Commons Attribution 4.0 (CC BY 4.0) License (http://creativecommons.org/licenses/by/4.0/). 